\title{
Stage IB2 Cervical Cancer AJCC v8
}

National Cancer Institute

\section{Source}

National Cancer Institute. Stage IB2 Cervical Cancer A/CC v8. NCI Thesaurus. Code C139740.

Stage IB2 includes: T1b2, Any N, M0. T1b2: Tumor with clinically visible lesion more than $4.0 \mathrm{~cm}$ in greatest dimension. M0: No distant metastasis. (AJCC 8th Ed.) 